\title{
Korrespondenzen.
}

\section{Zur Pantoponwirkung.}

In einer Arbeit über die Bedeutung des Pantopons ${ }^{1}$ ) habe ich die Vermutung ausgesprochen, daß Zersetzungsprodukte des Skopolamins in der fertigen Pantopon-Skopolamin-Mischung die Ursache der von mir beobachteten Kollapswirkung seien, und habe ein Kriterium in der Braunfärbung des Kaliumpermanganats durch diese Mischung sehen wollen. Die Chemischen Fabriken F. Hoffmann, La Roche $\& ;$ Co., Basel und Grenzach machen mich jetzt darauf aufmerksam, daß schon das Pantopon allein die Fähigkeit besitzt, Kaliumpermanganat zu reduzieren. Die Kesselsche Probe ist deshalb für die Beurteilung der Kollapswirkung der fertigen Pantopon-Skopolamin-Mischung nicht geeignet.

Dr. Gräfenberg. 